\title{
Perceived Devaluation and Discrimination toward mental illness Scale (PDDs): Its association with sociodemographic variables and interpersonal contact in a Mexican sample
}

\author{
Jazmín Mora-Ríos, ${ }^{1}$ Miriam Ortega-Ortega ${ }^{2}$
}

Dirección de Investigaciones Epidemiológicas y Sociales, Instituto $\mathrm{Na}^{-}$ cional de Psiquiatría Ramón de la Fuente Muñiz, Ciudad de México, México.

2 Programa de Maestría y Doctorado de Ciencias Médicas y Odontológicas, Universidad $\mathrm{Na}^{-}$ cional Autónoma de México, Ciudad de México, México.

\section{Correspondence:}

Jazmín Mora Ríos

Dirección de Investigaciones Epidemiológicas y Psicosociales, Instituto Nacional de Psiquiatría Ramón de la Fuente Muñiz.

Calz. México-Xochimilco 101,

San Lorenzo Huipulco

Tlalpan, 14370

Ciudad de México, México.

Phone: 55 4260-5158

Email: morari@imp.edu.mx

Received: 20 August 2019

Accepted: 5 February 2020

\section{Citation:}

Mora-Ríos, J., \& Ortega-Ortega, M (2021). Perceived Devaluation and Discrimination toward mental illness Scale (PDDs): Its association with sociodemographic variables and interpersonal contact in a Mexican sample. Salud Mental, 44(2), 75-82.

DOI: $10.17711 /$ SM.0185-3325.2021.011

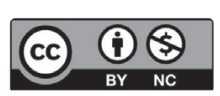

\begin{abstract}
Introduction. Research about stigma on mental illness in different sociocultural contexts is crucial to guide international efforts to reduce discrimination. Objective. Analyze the psychometric properties of the Perceived Devaluation and Discrimination (PDD) scale adapted for the Mexican population and its relationship with sociodemographic variables and interpersonal contact. Method. The study was based on a psychometric and cross-sectional design. The PDD scale was applied to a sample of 295 participants recruited through community programs in the south of Mexico City. Data were analyzed using confirmatory factor analysis to identify the subscales of PDDs. These subscales were compared by age, gender, and education using a univariate analysis. One-way analysis of variance (ANOVA) was then performed to determine whether there were differences in educational level between three PDDM-subscales. Results. The PDD scale obtained an adequate global internal consistency $(\alpha=.78)$. Three PDDs factors were identified: myths and stereotypes, favorable attitudes, and social exclusion, which explain $57.8 \%$ of the total variance. The results shows an $X^{2} \mathrm{SB}=140.88(d f=143$, $p=.05, C F I=1, R M S E A=.000, C l[.000, .029])$. Other findings showed significant differences in favorable attitudes toward mental illness subscale by gender and age. The ANOVA results for the social perception of the devaluation subscale reveal that those with a higher educational level could be more aware about devaluation in society toward people with mental illness than other groups with lower education $(F=4.88, p=.005)$. Discussion and conclusion. The PDD-M scale adapted in Mexico is a culturally valid and reliable measure that could be useful for evaluating the variations and commonalities of public stigma in comparative studies between Latino populations and other international research contexts.
\end{abstract}

Key words: Confirmatory factor analysis, Perceived Devaluation and Discrimination (PDD-M) Scale adapted in Mexico, mental illness, public stigma.

\section{RESUMEN}

Introducción. La investigación acerca del estigma de la enfermedad mental en distintos contextos sociales es fundamental para combatir la discriminación. Objetivo. Analizar las propiedades psicométricas de la Escala de Percepción de la Devaluación y la Discriminación hacia las enfermedades mentales adaptada en México (PDD) y su relación con variables sociodemográficas y el contacto interpersonal. Método. Se utilizó un diseño transversal ex post facto. Se aplicó la escala PDD-M en población adulta $(n=295)$ de la Ciudad de México. Los datos se analizaron mediante un análisis factorial confirmatorio y análisis multivariados. Resultados. Se identifican tres áreas del PDD-M: mitos y estereotipos, actitudes favorables y percepción social de la devaluación y discriminación, que explican el $57.8 \%$ de la varianza. Se obtuvo un buen ajuste del modelo $\mathrm{X}^{\mathrm{SB}}=140.88(d f=143, p=.05, \mathrm{CFI}=1, \mathrm{RMSEA}=.000, \mathrm{Cl}[.000, .029])$. La consistencia interna global de la prueba $(\alpha=.78)$ fue adecuada. Los resultados muestran diferencias significativas por género, edad y escolaridad. El análisis multivariado reveló que quienes tenían mayor nivel educativo eran más conscientes de la devaluación y la discriminación que quienes tenían escolaridades más bajas $(F=4.88, p=.005)$. Discusión y conclusión. Se obtuvo una medición culturalmente válida y confiable del estigma público de la enfermedad mental (PDD-M) que puede servir para impulsar la investigación en esta línea a través de estudios comparativos en América Latina y en otros contextos internacionales.

Palabras clave: Análisis factorial confirmatorio, Escala de Percepción de la Devaluación y Discriminación (PDDs), enfermedad mental, estigma público. 


\section{INTRODUCTION}

Public stigma refers to the stereotypes, prejudices, and discrimination existing in society toward mental illness and those affected by it (Corrigan, 1998; Corrigan \& Watson, 2007). In recent years, research on stigma and discrimination in mental illness in Latin America has increased. One of the main interests has been to develop measures adapted to this sociocultural context (Mascayano et al., 2016).

Studies carried out to date show that public stigma focuses on two factors: individuals' perceptions of other people's beliefs regarding the stigmatized group, and individuals' perceptions of other people's views of them as members of that group. There are measurements that incorporate one or both these components. Interpersonal contact is one of the variables that has been most widely explored in stigma research. It has been found that interpersonal contact, or closeness to persons with mental illness, does not necessarily reduce stigma and discrimination (Couture \& Penn, 2003; Pettigrew \& Tropp, 2006). However, various studies have found evidence for this association (Angermeyer, Matschinger, Carta, \& Schomerus, 2014; Corrigan, Morris, Michaels, Rafacz, \& Rüsch, 2012).

The Perceived Devaluation and Discrimination (PDD) Scale is one of the most widely-applied measurements in international research on stigma and discrimination (Brohan, Slade, Clement, \& Thornicroft, 2010; Link, Yang, Phelan, \& Collins, 2004; Zieger et al., 2016). It is a one-dimensional instrument originally designed by Link (1987) consisting of twelve questions that measure individuals' perceptions of social attitudes regarding mental illness. This scale has also been used to evaluate expected rejection due to mental illness. However, there has been some criticism of this measure, particularly as regards the ambiguity of certain terms, for example, using most people as a reference (Yang \& Link, 2016).

This scale has been adapted for its use in Germany (Matschinger, Angermeyer, \& Link, 1991), China (Lee, 2001), Sweden (Björkman, Svensson, \& Lundberg, 2007), and India (Zieger et al., 2016). Specifically, in the case of the PDD Scale, there are two adapted psychometric versions in Spanish. One is for Latin Americans living in the United States (Interian et al., 2010), and the other is a 22item version developed in Spain (Martínez-Zambrano et al., 2016). The latter was adapted to measure internalized stigma in people with mental health problems.

Both versions have shown adequate levels of reliability (Cronbach's alpha .86 and .91). In the Spanish version adapted by Interian et al. (2010), there is no evidence that the scale is one-dimensional. Two factors are identified, one related to negative perceptions and the other to positive ones. Likewise, in the article by Angermeyer et al. (2014), more than one subscale was identified.

Most research on stigma is based on measurements designed in a Western context (Schomerus et al., 2012;
Evans-Lacko, Henderson, \& Thornicroft, 2013; Parcesepe \& Cabassa, 2013), with very little having been undertaken in Latin America (Mascayano, et al., 2016; Fresán, Robles-García, Martínez-López, Tovilla-Zárate, \& Madrigal, 2018). One challenge is to have measurements that will allow us to evaluate the common ways and expressions of stigma, such as those that are more culturally specific (Yang, Thornicroft, Alvarado, Vega, \& Link, 2014).

This study was part of a broader cross-cultural study using mixed methods on stigma about mental illness in health personnel, people with mental health disorder diagnosis, and the general population, including relatives whose main objective was to develop interventions designed to reduce stigma in the target population. Information related to the cultural adaptation of the scales, including PDDs, was published in a previous article (Mora-Ríos, Bautista-Aguilar, Natera, \& Pedersen, 2013a).

The current study has two specific aims: 1. to undertake a confirmatory factor analysis of the PDD Scale adapted in Mexico to identify the factors that account for the perception of devaluation and discrimination regarding mental illness in the urban adult population; and 2. to assess the relation between PDD-M subscales and sociodemographic variables (sex, age, education, employment) and another variables related to interpersonal contact (type of informant, contact with people with mental illness, and frequency of contact). Understanding these relationships could be useful for the implementation of measures to reduce stigma and discrimination in this population.

\section{METHOD}

Data collection in Mexico was carried out from January 2009 to July 2010. Details of the methodologies have been published elsewhere (Mora-Ríos, Natera-Rey, Bautista-Aguilar, \& Ortega-Ortega, 2013b; Pedersen, 2009). This paper includes only information related to the objectives mentioned above.

\section{Study design and participants}

Based on a cross-sectional study design, the sample included 295 participants from two groups. A sizeable portion $(46 \%)$ of participants in this study were family members of persons with mental illness. They were recruited at community centers and in psychoeducation groups at specialized mental health care clinics. None of the relatives reported going to these places for their own mental health problems.

The rest of the participants were recruited through community programs in a south Mexico City neighborhood, who were mainly heads of household and preschool teachers, as well as a group of gardeners. Table 1 shows the sociodemographic characteristics of participants. 
Table 1

Sociodemographic characteristics of participants

\begin{tabular}{|c|c|c|}
\hline & $\begin{array}{c}\text { Total } \\
(n=295)\end{array}$ & $\%$ \\
\hline \multicolumn{3}{|l|}{ Sex } \\
\hline Female & 219 & 76 \\
\hline Male & 56 & 24 \\
\hline \multicolumn{3}{|l|}{ Age } \\
\hline (Years) & \multicolumn{2}{|c|}{$18-79$} \\
\hline (mean) & \multicolumn{2}{|c|}{$(42)$} \\
\hline \multicolumn{3}{|l|}{ Type of informant } \\
\hline Family member & 137 & 46 \\
\hline General population & 158 & 54 \\
\hline \multicolumn{3}{|l|}{ Education } \\
\hline Elementary & 74 & 26.1 \\
\hline Middle school & 82 & 29 \\
\hline High school & 63 & 22.3 \\
\hline Bachelor's or graduate degree & 64 & 22.6 \\
\hline \multicolumn{3}{|l|}{ Employment status } \\
\hline Economically active & 234 & 82 \\
\hline Economically inactive & 52 & 18 \\
\hline \multicolumn{3}{|l|}{ Knows someone with mental illness } \\
\hline Yes & 199 & 70 \\
\hline No & 86 & 30 \\
\hline \multicolumn{3}{|l|}{ Frequency of contact } \\
\hline Never/almost never & 106 & 44 \\
\hline Seldom & 24 & 10 \\
\hline Frequently & 110 & 46 \\
\hline
\end{tabular}

\section{Measurements}

The PDD Scale consists of twelve statements measuring the perception of devaluation and discrimination toward persons with mental illnesses. Responses indicate the level of agreement with each statement. Rather than inquiring about the informants' own perceptions, statements are presented in the form "Most people think or believe...," in order to reduce the factor of social desirability. Responses are given on a fourpoint Likert scale $(0=$ complete disagreement to $3=$ complete agreement). The instrument has a global internal consistency of .76 (Cronbach's alpha), which varies from .75 to .88 in international studies (Angermeyer et al., 2014; Ahn et al., 2015; Matschinger et al., 1991; Lee, 2001; Björkman et al., 2007).

The PDDs version that was semantic and culturally adapted to the adult urban population of Mexico was used in the study. It consisted of the 12 questions originally proposed by Link (1987) plus seven included for reasons of cultural relevance, making a total of 19 questions. As seen in Table 2, these seven items comprised the myths and stereotypes subscale (Mora-Ríos, Bautista-Aguilar, Natera, \& Pedersen, 2013a).

The questionnaire also contained a section on sociodemographic aspects (sex, age, education, employment) and three questions exploring interpersonal contact. Interpersonal contact was measured by respondents' answers to the following questions: "Do you personally know someone with mental health problems?" $(1=$ Yes, 2 = No); "What is your relationship to that person?" (e.g., relative, friend, classmate, etc.), and "Have you been in touch with that person?" ( $1=$ Yes, $2=$ No). A total of $69 \%$ of the entire sample reported knowing someone with mental health problems, $55 \%$ mentioned a family member, $16 \%$ a friend, and the remaining $29 \%$ acquaintances from school, work, or the community.

\section{Procedure}

Authorization was obtained from all participating institutions, which were briefed about our objectives. The research team briefed prospective subjects and invited their voluntary participation, emphasizing that the project was independent of the institutions.

Focal groups were conducted as part of a broad strategy to investigate the nature of discriminatory opinions, attitudes, and practices regarding mental illness. Interviews lasted an average of 90 minutes, and the application of the instrument an additional 20 minutes; PDDs were completed prior to the interviews in order to avoid influencing participants' opinions. At the end of their participation, respondents were thanked for their collaboration and given an opportunity to ask questions to clarify any concerns. A more extensive description of the organization of the groups and the qualitative findings can be found in a previous publication (Mora-Ríos, Natera-Rey, Bautista-Aguilar, \& Ortega-Ortega, 2013b).

\section{Data analysis}

Confirmatory analyses were carried out with EQS structural equation modeling (SEM) software (version 6.2) (Bentler, 2006). To determine whether there were differences in scholarity between three PDDM-subscales, a one-way analysis of variance (ANOVA) was performed with posthoc Bonferroni.

A comparative analysis was undertaken to study the relationship among PDD-M and sociedemographic variables and interpersonal contact. Due to the interest in establishing comparisons by age, contrasting younger with older people and employment, those who were active $v s$. those who were not, variables were dichotomized, including those concerning interpersonal contact.

The PDD-M subscales were considered dependent variables and the independent variables were sex (female/ male), type of respondent (family/general population), age (43 and under/44 and over), employment status (employed/ unemployed), knowing a person with mental illness (yes/ no), and frequency of contact (yes/no). 
Table 2

Means and standard deviations on the Perceived Devaluation and Discrimination (PDD) Scale, general population $(n=295)$

\begin{tabular}{|c|c|c|}
\hline Questions & Mean & $S D$ \\
\hline \multicolumn{3}{|l|}{ Myths and associated stereotypes (alpha $=.70)$} \\
\hline 13. People think women are more prone to mental illness. ${ }^{*}$ & 1.22 & .91 \\
\hline 14. People think people with mental illness tend to be more violent. ${ }^{*}$ & 2.03 & .86 \\
\hline 15. People are afraid in the presence of people with mental illness. ${ }^{*}$ & 2.00 & .83 \\
\hline 16. People think people with mental illness have a weak character. ${ }^{*}$ & 1.49 & .88 \\
\hline 17. Family members of persons with mental illness are ashamed of them.* & 1.58 & .93 \\
\hline 18. Schools would not accept a person who has been hospitalized for mental illness. ${ }^{*}$ & 1.65 & .85 \\
\hline 19. People think that people with mental illness are being punished for something they did wrong.* & 1.04 & .88 \\
\hline \multicolumn{3}{|l|}{ Explained variance $=39.37 \%$} \\
\hline \multicolumn{3}{|l|}{ Favorable attitudes toward persons with mental illness (alpha $=.70)$} \\
\hline 1. People would accept someone who had mental illness as a friend. & 1.76 & .79 \\
\hline 2. Someone receiving psychiatric services is just as intelligent as any other person. & 1.67 & .86 \\
\hline 3. Someone who has been hospitalized for a mental illness is just as trustworthy as any other person. & 2.02 & .72 \\
\hline 4. People would accept someone who has recovered from mental illness as a teacher. & 2.02 & .82 \\
\hline 8. People would hire someone who has been hospitalized for a mental illness, if they were qualified. & 1.78 & .82 \\
\hline $\begin{array}{l}\text { 10. The community would give equal treatment to someone who had been hospitalized for mental illness. } \\
\text { Explained variance }=11.15 \%\end{array}$ & 1.68 & .82 \\
\hline \multicolumn{3}{|l|}{ Social perception of devaluation and discrimination (alpha $=.68$ ) } \\
\hline 5. People think that seeking psychiatric services is a mark of personal failure. & 1.46 & .87 \\
\hline 6. Most people would not hire someone who has been hospitalized for mental illness to take care of their children. & 1.67 & .97 \\
\hline 7. People devalue those who have received psychiatric care. & 1.82 & .84 \\
\hline 9. Employers would not consider a job application from someone who has been hospitalized for mental illness. & 1.68 & .88 \\
\hline 11. Young people would not be willing to go on a date with someone who has been hospitalized for mental illness. & 1.68 & .86 \\
\hline $\begin{array}{l}\text { 12. People would not take seriously the opinions of someone who has been hospitalized for mental illness. } \\
\text { Explained variance }=7.2 \%\end{array}$ & 1.61 & .82 \\
\hline
\end{tabular}

Notes: Overall reliability (Cronbach's alpha) $=.78$

*Items added during the cultural adaptation process in Mexico.

\section{Ethical considerations}

This study was approved by the Ethics Committee of the Instituto Nacional de Psiquiatría Ramón la Fuente Muñiz (INPRFM, National Institute of Psychiatry). Informed consent forms used throughout the process guaranteed the anonymity and confidentiality of the information.

\section{RESULTS}

\section{Confirmatory factor analysis of the PDD-M Scale}

Differentiation analysis of the questions showed item-total correlation coefficients of more than .30 , and none were eliminated. A construct validity analysis was subsequently undertaken to confirm the correct assignment of questions to each subscale and to determine their inclusion or elimination in the final scale.

A confirmatory factor analysis was carried out using the maximum likelihood method with oblique rotation through the program EQS (version 6.1) (Bentler, 2006) in order to obtain a revalidated instrument with a robust methodology. The three conceptually consistent factors suggested by the exploratory factor analysis were used as a baseline. It is interesting to observe that all the items added during the semantic validation in Mexico were grouped within the first factor. The first factor included seven items added in Mexico during the semantic validation, whose contents are related to myths and stereotypes about mental illness, the second includes six questions regarding favorable attitudes, and the third comprises another six questions concerning social perception of the devaluation and discrimination toward people with mental illness. These three dimensions explain $57.8 \%$ of the total variance. The result shows an SB scaled $X^{2}=140.88(d f=143, p=.05, C F I=1, R M S E A=$ $.000, C I[.000, .029])$. Figure 1 shows the PDD-M subscales and their correlations, as well as the standardized regression weights for each of the questions assigned to each factor.

Table 2 shows the mean values obtained in each area and the variance explained by factor. The internal consistency of the instrument in this most rigorous analysis corresponded to a Cronbach's alpha of .78, using SPSS (version 21) (IBM Corporation, 2012). 


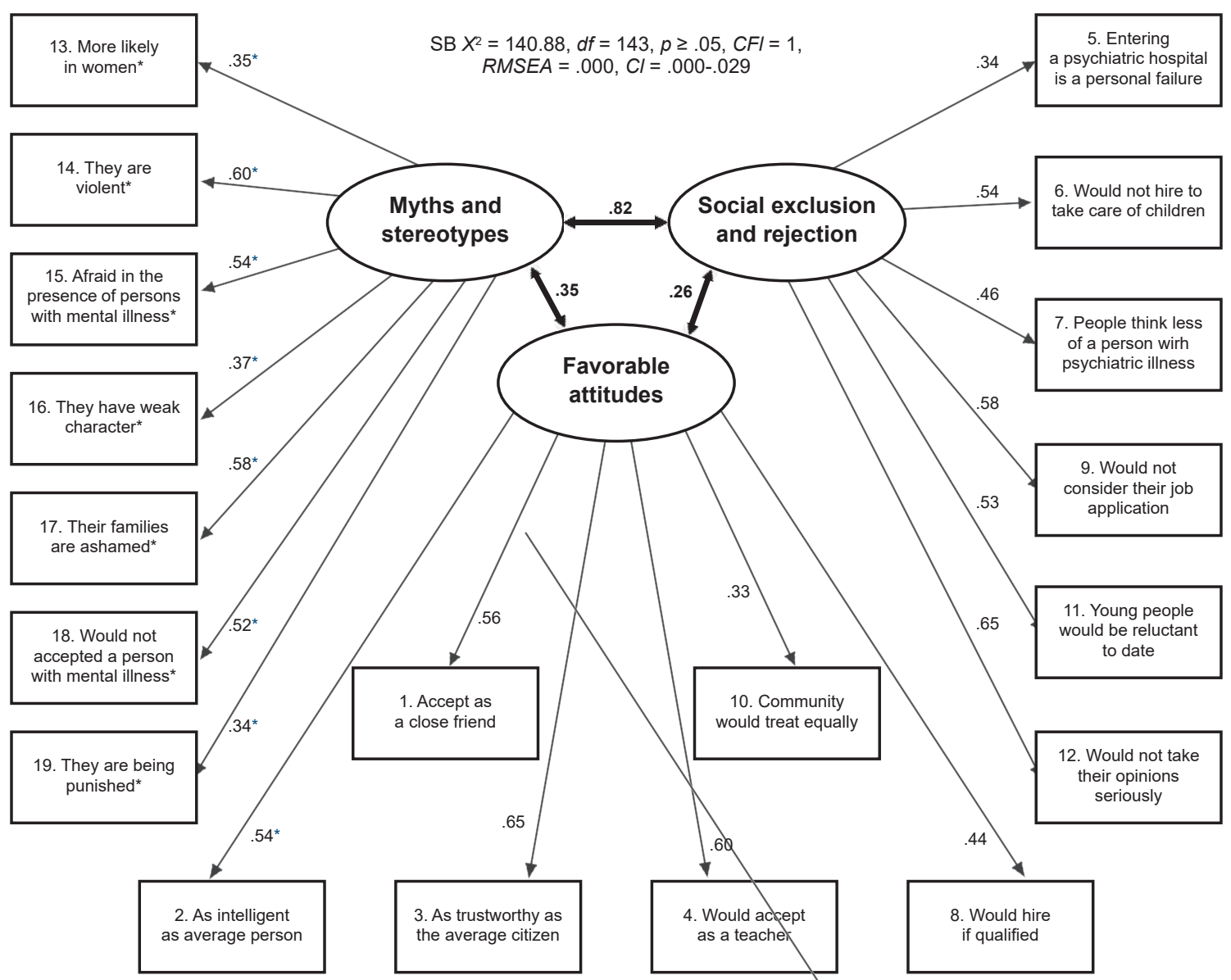

Figure 1. Confirmatory factor analysis of the PDD Scale $(n=295)$.

* These items were added during the semantic adaptation of PDDs in Mexico.

\section{Relationship of PDD-M subscales and sociodemographic variables}

With the PDD-M subscales identified, a univariate analysis was carried out. As was described in the analysis section, other variables were regrouped to improve the distribution of the responses. Table 3 shows the findings from a comparative analysis with a Student's t-test.

The results show significant differences in favorable attitudes toward mental illness. Women perceived more favorable attitudes in society $(M=11.21, S D=3.08)$ than men $(M=10.24, S D=2.99)(t=2.22, d f=275, p=.05)$. There were also significant differences by type of informant. As seen in Table 3, the general population perceived more favorable attitudes $(M=11.37, S D=2.70)$ than family members $(M=10.56, S D=3.40)(t=2.18, d f=249, p=$ $.05)$. Likewise there were differences by age, with those 43 and under $(M=11.35, S D=2.99)$ showing more favorable attitudes than those 44 and over $(M=10.54, S D=3.13)(t=$ $2.17, d f=275, p=.05$ ).

For the social perception of the devaluation subscale, the significant variables were age, employment status, and education, with higher scores for the perception of devaluation in the younger age group $(M=10.29, S D=3.35)$, than older group $(M=9.38, S D=3.13)(t=2.26, d f=264$, $p=.05)$, in the economically inactive group $(M=10.82$, $S D=3.12)$, than in the active group $(M=9.63, S D=3.30)$, $(t=2.25, d f=256, p=.05)$.

Sex was the only variable in which there were significant differences in the myths and stereotypes subscale, with scores for women being higher $(M=11.36, S D=3.54)$ than those for men $(M=10.14, S D=4.01),(t=2.28, d f=258$, $p=.05)$.

As can be seen in Table 3, the ONEWAY results for the social perception of the devaluation subscale showed that higher scores were found among those with at least a bachelor's degree $(11.10, \pm 3.07, p \leq .05)$ than among those who had only completed elementary $(9.12, \pm 3.41, p \leq .05)$ or middle school $(9.31, \pm 3.30, p=.05)$. This shows that those with higher level of education might be more aware of devaluation in society toward people with mental illness than other groups with lower level of education. 
Table 3

$P D D$ subscales and related variables

\begin{tabular}{|c|c|c|c|c|c|c|c|c|c|}
\hline \multirow[b]{2}{*}{ Variables } & \multicolumn{3}{|c|}{ Favorable attitudes } & \multicolumn{3}{|c|}{ Perception of devaluation } & \multicolumn{3}{|c|}{ Myths and stereotypes } \\
\hline & Mean & $S D$ & $T$ & Mean & $S D$ & $T$ & Mean & $S D$ & $T$ \\
\hline \multicolumn{10}{|l|}{ Sex } \\
\hline Female & 11.21 & 3.08 & $2.22^{*}$ & 10.00 & 3.30 & 1.06 & 11.36 & 3.54 & $2.28^{*}$ \\
\hline Male & 10.24 & 2.99 & & 9.50 & 3.19 & & 10.14 & 4.01 & \\
\hline \multicolumn{10}{|l|}{ Participant } \\
\hline Family member & 10.56 & 3.40 & $2.18^{*}$ & 10.08 & 3.06 & .90 & 10.80 & 3.86 & -1.10 \\
\hline General population & 11.37 & 2.70 & & 9.71 & 3.44 & & 11.30 & 3.53 & \\
\hline \multicolumn{10}{|l|}{ Age } \\
\hline 18- 43 years & 11.35 & 2.99 & $2.17^{*}$ & 10.29 & 3.35 & $2.26^{*}$ & 11.36 & 3.79 & 1.47 \\
\hline $44-79$ years & 10.54 & 3.13 & & 9.38 & 3.13 & & 10.69 & 3.53 & \\
\hline \multicolumn{10}{|l|}{ Employment status } \\
\hline Economically active & 11.13 & 3.03 & -1.59 & 9.63 & 3.30 & $2.25^{\star}$ & 11.05 & 3.72 & -.30 \\
\hline Economically inactive & 10.35 & 3.29 & & 10.82 & 3.12 & & 10.86 & 3.65 & \\
\hline \multicolumn{10}{|l|}{ Education } \\
\hline Elementary & 10.06 & 3.14 & 2.97 & 9.12 & 3.41 & $4.88^{* *}$ & 10.93 & 3.65 & 1.65 \\
\hline Middle school & 10.93 & 3.02 & & 9.32 & 3.30 & & 10.38 & 3.93 & \\
\hline High school & 11.42 & 2.57 & & 10.21 & 3.05 & & 11.58 & 3.53 & \\
\hline Bachelor's and graduate degrees & 11.48 & 3.25 & & 11.10 & 3.07 & & 11.59 & 3.63 & \\
\hline
\end{tabular}

${ }^{*} p \leq .05 ;{ }^{* *} p \leq .005$.

\section{DISCUSSION AND CONCLUSION}

The PDD-M structure identified in the urban population in Mexico includes three dimensions: myths and stereotypes, favorable attitudes, and social perception of devaluation. The main factor, called myths and stereotypes, was incorporated through seven questions that were culturally relevant to the adult population in Mexico. The second factor, called favorable attitudes, which correspond to the factorial structure reported in previous studies (Angermeyer et al., 2014; Interian et al., 2010) and the third factor, called social perception of devaluation and discrimination. These results confirm the evidence of the psychometric validity and reliability of the PDD-M and could be usefully applied in the Hispanic population. The global internal consistency obtained (Cronbach's alpha $=.78$ ) corresponds to the rates reported in researches that have obtained the validity of this measurement and range from .75 to .89. (Matschinger et al., 1991; Lee, 2001; Björkman et al., 2007; Angermeyer et al., 2014; Ahn et al., 2015).

On the other hand, the high correlation between the first and second factors was .82 . This suggests the use of a factorial structure comprising two factors. When this analysis was undertaken, the explained variance and the reliability were similar (Cronbach's alpha $=.77$ ). However, due to the interest in maintaining the cultural differences of the items created locally, it was decided to maintain the structure of three factors. This could be useful for establishing a comparative analysis with other Hispanic regions (factor 1 and 2), maintaining the items locally relevant for Mexico's population (factor 1). The next section shows the analysis of the PDD-M scale factorial structure with three factors and its relationship with other variables of interest.

Results are consistent with previous studies in Hispanic populations, in which the factorial structure of PDD scale did not constitute a one-dimensional scale (Interian et al., 2010), as the original authors proposed (Link, 1987). It is important to note that the version of the PDDs we used in this study is different from those utilized in other studies. The one we used comprises 19 items, including seven added during the cultural adaptation of the instrument to the Mexican population (Mora-Ríos et al., 2013a). Due to the methodological differences that exist in the studies, findings are not comparable. For example, in the Interian et al. (2010) version with the Hispanic population, the PDD items were adapted to evaluate depression, whereas in the Spanish version of the PDDs, the adaptation was undertaken to evaluate self-stigma. In the German version of the PDDs, although they identified two factors, positive and negative related to the perception of mental illness, the authors ultimately decided to maintain a single dimension by eliminating the items evaluating positive aspects of perception (Angermeyer, 2014).

In contrast with the Angermeyer study (2014), in this study we found a high correlation (.82) between the myths and stereotypes factor, which confirmed the conceptual applicability of this factor in the general construct. The decision to keep the factors separate is based on the purpose of the research. The first factor will allow us to identify the myths and stereotypes in Mexico and other Spanish- 
speaking countries and populations, while the second and third factor will be useful for establishing transcultural comparisons in non-Hispanic regions. Thus, it is possible to capture the specific expressions of stigma at the local level, than those that are more universal, since it is one of the main limitations of the stigma measurements in international studies, which were unable to incorporate the cultural aspects of stigma toward mental illness (Yang et al., 2014).

The inclusion of positive attitudes is crucial to the development of broad indicators regarding the social perception of mental illnesses; it is for this reason that we call this factor "favorable attitudes." It is worth highlighting our finding, one which runs contrary to studies from other sociocultural contexts (Angermeyer et al., 2014; Razali \& Ismail, 2014), of more favorable attitudes in the general population than in family members, which might be explained as a result of the emotional burden on family members contending with the illness of a close one (Corrigan \& Miller, 2004). A sizeable portion $(46 \%)$ of participants in this study were family members of persons with mental illness.

Women seem aware of public stigma and also perceive more favorable attitudes toward mental illness than men (Corrigan \& Watson, 2007; Martínez-Zambrano et al., 2016; Vicario Cañas \& Moral-Jiménez, 2016). It is important to stress that the PDD scale is oriented toward the evaluation of "what others think," rather than the perceptions of informants themselves, in order to capture the social perception of devaluation and discrimination regarding mental illness. Although this approach reduces the social desirability effect, it also constitutes a limitation of the study, as the participants' own perceptions were not recorded, as reported in other studies (Vicario Cañas \& Moral-Jiménez, 2016).

Other findings of this study reveal that educational level has an impact on the social perception of devaluation and discrimination, which suggests that participants with higher educational levels could influence trends regarding the devaluation of people with mental illness. Accordingly, this group shows more awareness of public stigma toward the mental illness present in society. These data suggest the need to implement psychoeducational programs to provide information on myths and stereotypes in interventions designed to reduce the stigma and discrimination associated with mental illness.

\section{Limitations of the study}

The extent of our findings should be considered with caution because of the small size sample, and since the sample was not randomly selected, findings cannot be generalized to other population groups.

Further research is required to establish the validity and reliability of the PDDs-M across different groups. Although recent studies have reported a significant impact of variables related to the level of interpersonal contact on the social perception of devaluation and discrimination (Angermeyer et al., 2014; Thornicroft et al., 2016), the present study found no evidence of this association.

Future studies should incorporate other psychosocial variables and more precise indicators, which would make it possible to assess the possible impact of interpersonal contact, including cultural variations. Another challenge is to identify social perception regarding the different types of mental illness (Angermeyer et al., 2014; Rüsch, Evans-Lacko, \& Thornicroft, 2012), as greater rejection has been found toward serious psychiatric disorders such as bipolar disorder and schizophrenia than toward affective and mood disorders (Ahn et al., 2015).

The findings of this study showed that the adapted version of PDDs in Mexico is a valid, reliable measure to evaluate public stigma towards mental illness that could be useful to establish comparative analyses in transcultural studies in Latin America. Sociocultural factors, specifically related with myths and stereotypes, are crucial to understanding the complexity of stigmatization processes and their effects on different contexts (Cabassa et al., 2014). They would support a concerted effort to develop public policies designed to reduce stigma and discrimination at the local and international level (Pescosolido, 2013; Pescosolido, Medina, Martin, \& Long, 2013).

\section{Funding}

This study was funded by Sectorial Fund of Research on Health and Social Security (FOSSIS-CONSEJO NACIONAL DE CIENCIA Y TECNOLOGÍA (SALUD-2007-C01-69261).

\section{Conflict of interest}

The authors declare they have no conflicts of interest.

\section{Acknowledgements}

We wish to acknowledge the contributions of all those whose participated in the study, including the participating institutions, and the team of interviewers (Natalia Bautista Aguilar and Alva Lilia Licea Solano) and Enrique Méndez (MC) for his help with the statistical analysis and reviewing this manuscript.

\section{REFERENCES}

Ahn, J.-H., Kim, W.-H., Choi, H.-J., Jeon, J.-Y., Song, I.-G. \& Bae, J.-N. (2015). Stigma of mental illness as perceived by North Korean defectors living in South Korea. Psychiatry Investigation, 12(1), 9-15. doi: 10.4306/pi.2015.12.1.9

Angermeyer, M. C., Matschinger, H., Carta M. G., \& Shomerus, G. (2014). Changes in the perception of mental illness stigma in Germany over the last two decades. European Psychiatry, 29(6), 390-395. doi: 10.1016/j.eurpsy.2013.10.004

Bentler, P. M. (2006). EQS Structural Equation Model Program. Encino, CA; Multivariate Software Inc. Available from http://www.econ.upf.edu/ satorra/ CourseSEMVienna2010/EQSManual.pdf

Björkman, T., Svensson, B., \& Lundberg, B. (2007). Experiences of stigma among people with severe mental illness. Reliability, acceptability and construct validity of the Swedish versions of two stigma scales measuring devaluation/ discrimination and rejection experiences. Nordic Journal Psychiatry, 61(5), 332-338. doi: 10.1080/08039480701642961 
Brohan, E., Slade, M., Clement, S., \& Thornicroft, G. (2010). Experiences of mental illness stigma, prejudice and discrimination: a review of measures. BMC Health Services Research, 10(1), 80. doi: 10.1186/1472-6963-10-80

Cabassa, L. J., Gomes, A., Meyreles, Q., Capitelli, L., Younge, R., Dragatsi, D., ... Lewis-Fernández, R. (2014). Primary health care experiences of Hispanics with serious mental illness: A mixed methods study. Administration and Policy in Mental Health, 41(6), 724-736. doi: 10.1007/s10488-013-0524-2

Corrigan, P. W. (1998). The impact of stigma on severe mental illness. Cognitive and Behavioral Practice, 5(2), 201-222. doi: 10.1016/S1077-7229(98)80006-0

Corrigan, P. W., \& Miller, F. E. (2004). Shame, blame, and contamination: A review of the impact of mental illness stigma on family members. Journal of Mental Health, 13(6), 537-548. doi: 10.1080/09638230400017004

Corrigan, P. W., \& Watson, A. C. (2007). The stigma of psychiatric disorders and the gender, ethnicity and education of the perceiver. Community Mental Health Journal, 43(5), 439-458. doi: 10.1007/s10597-007-9084-9

Corrigan, P. W., Morris, S. B., Michaels, P. J., Rafacz, J. D., \& Rüsch, N. (2012). Challenging public stigma of mental illness: a meta-analyses of outcome studies. Psychiatric Services, 63(10), 963-973. doi: 10.1176/appi.ps.201100529

Couture, S., \& Penn, D. (2003). Interpersonal contact and the stigma of mental illness: A review of the literature. Journal of Mental Health, 12(3), 291-305. doi: 10.1080/09638231000118276

Evans-Lacko, S., Henderson, C., \& Thornicroft, G. (2013). Public knowledge, attitudes and behaviour regarding people with mental illness in England 20092012. The British Journal of Psychiatry, 202(s55), s51-s57. doi: 10.1192/bjp. bp.112.11297

Fresán, A., Robles-García, R., Martínez-López, N., Tovilla-Zárate, C., \& Madrigal, E. (2018). Stigma and perceived aggression towards schizophrenia in female students of medicine and psychology. Salud Mental, 41(5), 207-212. doi: 10.17711/SM.0185-3325.2018.031

IBM Corporation. (2012). IBM SPSS Statistics for Windows, Version 21.0. Armonk, NY: IBM Corp.

Interian, A., Ang, A., Gara, M. A., Link, B. G., Rodriguez, M. A., \& Vega, W. A. (2010). Stigma and depression treatment utilization among Latinos: utility of four stigma measures. Psychiatric Services, 61(4), 373-379. doi: 10.1176/appi. ps.61.4.373

Lee, K. H. (2001). A study on the stigma about persons with mental disability. Seoul: Ewha Womans University.

Link, B. G. (1987). Understanding labeling effects in the area of mental disorders: An assessment of the effects of expectations of rejection. American Sociological Review, 52(1), 96-112. doi: 10.2307/2095395

Link, B. G., Yang, L. H., Phelan, J. C., \& Collins, P. Y. (2004). Measuring mental illness stigma. Schizophrenia Bulletin, 30(3), 511-541. doi: 10.1093/ oxfordjournals.schbul.a007098

Martínez-Zambrano, F., Pizzimenti, M., Barbeito, S., Vila-Badia, R., Comellas, G., Escandell, M. J., ... Ochoa, S. (2016). Spanish version of the Link's Perceived Devaluation and Discrimination Scale. Psicothema, 28(2), 201-206. doi: 10.7334/psicothema2015.89

Mascayano, F., Tapia, T., Shilling, S., Alvarado, R., Tapia, E., Lips, W., \& Yang, L. (2016). Stigma toward mental illness in Latin America and the Caribbean. A systematic review. Brazilian Journal of Psychiatry, 38(1), 73-85. doi: 10.1590/1516-4446-2015-1652

Matschinger, H., Angermeyer, M. C., \& Link, B. C. (1991). Variation of response structures in relation to degree of personal involvement -a methodological study using exemplified by the Discrimination Devaluation Scale. Psychotherapie Psychosomatik Medizinische Psychologie, 41(7), 278-283.
Mora-Ríos, J., Bautista-Aguilar, N., Natera, G., \& Pedersen, D. (2013a). Adaptación semántica de instrumentos de medidas sobre estigma y enfermedad mental en la Ciudad de México. Salud Mental, 36(1), 9-18. doi: 10.17711/SM.01853325.2013 .002

Mora-Ríos, J., Natera-Rey, G., Bautista-Aguilar, N., \& Ortega-Ortega, M. (2013b). Estigma público y enfermedad mental. Una aproximación desde la teoría de las representaciones sociales. In Flores-Palacios F, (Coordinator). Representaciones sociales y contexto de investigación con perspectiva de género (pp. 45-80). México: Centro Regional de Investigaciones Multidisciplinarias, UNAM.

Parcesepe, A. M., \& Cabassa, L. J. (2013). Public stigma of mental illness in the United States: a systematic literature review. Administration and Policy in Mental Health, 40(5), 384-399. doi: 10.1007/s10488-012-0430-z

Pedersen, D. (2009). Estigma y exclusión social en las enfermedades mentales: apuntes para el análisis y diseños de intervenciones. Acta Psiquiátrica y Psicológica de América Latina, 55(1), 39-50.

Pescosolido, B. A. (2013). The public stigma of mental illness: what do we think; what do we know; what can we prove? Journal of Health and Social Behavior, 54(1), 1-21. doi: 10.1177/0022146512471197

Pescosolido, B. A., Medina, T. R., Martin, J. K., \& Long, J. S. (2013). The "backbone" of stigma: identifying the global core of prejudice associated with mental illness. American Journal of Public Health, 103(5), 853-860. doi: 10.2105/ AJPH.2012.301147

Pettigrew, T. F., \& Tropp, L. R. (2006). A meta-analytic test of intergroup contact theory. Journal of Personality and Social Psychology, 90(5), 751-783. doi: 10.1037/0022-3514.90.5.751

Razali, S. M., \& Ismail, Z. (2014). Public stigma towards patients with schizophrenia of ethnic Malay: a comparison between the general public and patients' relatives. Journal of Mental Health, 23(4), 176-180. doi: 10.3109/09638237.2014.910644

Rüsch, N., Evans-Lacko, S., \& Thornicroft, G. (2012). What is a mental illness? Public views and their effects on attitudes and disclosure. Australian and New Zealand Journal of Psychiatry, 46(7), 641-650. doi: 10.1177/0004867412438873

Schomerus, G., Schwahn, C., Holzinger, A., Corrigan, P. W., Grabe, H. J., Carta, M. G., \& Angermeyer, M. C. (2012). Evolution of public attitudes about mental illness: a systematic review and meta-analysis. Acta Psychiatrica Scandinavica, 125(6), 440-452. doi: 10.1111/j.1600-0447.2012.01826.x

Thornicroft, G., Mehta, N., Clement, S., Evans-Lacko, S., Doherty, M., Rose, D., ... Henderson, C. (2016). Evidence for effective interventions to reduce mentalhealth-related stigma and discrimination. Lancet, 387(10023), P1123-1132. doi: 10.1016/S0140-6736(15)00298-6

Vicario Cañas, A., \& Moral-Jiménez, M. V. (2016). Actitudes hacia los trastornos mentales y su asociación percibida con delito: Estigma social. Salud \& Sociedad, 7(3), 254-269. doi: 10.22199/S07187475.2016.0003.00002

Yang, L. H., \& Link, B. G. (2016). Measurement of attitudes, beliefs and behaviors of mental health and mental illness. National Academy of Science.

Yang, L. H., Thornicroft, G., Alvarado, R., Vega, E., \& Link, B. G. (2014). Recent advances in cross-cultural measurement in psychiatric epidemiology: utilizing 'what matters most' to identify culture-specific aspects of stigma. International Journal of Epidemiology, 43(2), 494-510. doi: 10.1093/ije/dyu039

Zieger, A., Mungee, A., Schomerus, G., Ta, T. T., Dettling, M., Angermeyer, M. C., \& Hahn, E. (2016). Perceived stigma of mental illness: A comparison between two metropolitan cities in India. Indian Journal of Psychiatry, 58(4), 432-437. doi: $10.4103 / 0019-5545.196706$ 